\title{
Preface to the New Edition
}

This book first appeared in 1990, with a second edition in 1995. It was, until recently, the only single volume history of propaganda from the ancient world to the present day. No such volume can purport to be comprehensive, but it has proved necessary to update the final chapters and to add new ones that embrace the Balkan wars (including the 1999) Kosovo campaign and, of course, the so-called 'war' against international terrorism. As I write this new preface, the world is gearing up for another possible war against Saddam Hussein in Iraq. Leaflets have already been dropped there. This book attempts to place the conduct of propaganda during these events within a wider historical context. It retains its main thesis that propaganda is a much misunderstood word, that it is not necessarily the 'bad thing' that most people think it is. As a process of persuasion, it is value neutral. Rather, it is the intention behind the propaganda which demands scrutiny and it is that intention which begs value judgements not the propaganda itself.

Much has happened since 1995, not least the terrorist attacks on New York and Washington on 11 September 2001, or '9/11' as it is now currently being described in shorthand. We are in the middle of another major propaganda campaign, although it is often difficult for us to identify it for what it is because we are living through it. News and views are all around us, speculation is rife, sides are being polarized. Indeed, the issue of Iraq notwithstanding, we may be on the verge of the greatest propaganda campaign ever seen as the West struggles to convince the Muslim world that this is not a war against Islam when many in the Islamic world genuinely believe that it is. President George W. Bush warns that the United States is in it 'for the long haul'. If so, then we will see a new global struggle for hearts and minds that may be on a par with the Cold War. This book should, until its next edition, provide some clues as to how to identify propaganda for what it is, how it has evolved and - most importantly - to judge for oneself the intentions behind those undertaking it. 